\title{
Methylphenidate-Induced Acute Dystonic Reaction: A case report
}

Ayse Erdogan ${ }^{*}$ and Hakan Erdogan

Bursa Sevket Yilmaz Training and Research Hospital, Turkey

*Corresponding author: Ayse Erdogan, Deputy Chief of Staff, Bursa Sevket Yilmaz Training and Research Hospital, Turkey, Tel: 295 55175; E-mail: erdogansay@yahoo.com

Received date: October 06, 2015; Accepted date: November 03, 2015; Published date: November 09, 2015

Copyright: ( 2015 Erdogan A, et al. This is an open-access article distributed under the terms of the Creative Commons Attribution License, which permits unrestricted use, distribution, and reproduction in any medium, provided the original author and source are credited.

\begin{abstract}
Dystonia is a syndrome characterized by sustained muscle contractions frequently causing twisting and repetitive movements or abnormal postures. Dystonic reactions may be a complication of many drugs such as antipsychotics, anti-emetics and antidepressants. This report presents a 4-year-old healthy boy who was admitted to an emergency department with acute dystonia following the ingestion of methylphenidate, a stimulant pharmalogical agent used for the treatment for attention-deficit hyperactivity disorder. In conclusion, this report suggests that methylphenidate increase dopaminergic transmission can also trigger dystonic reaction in at healthy child.
\end{abstract}

Keywords: Methylphenidate; Acute dystonic reaction

\section{Introduction}

Methylphenidate (MPH), a psychostimulant affecting both the dopaminergic and the noradrenergic systems, has an established safety and efficacy profile and is one of the most frequently prescribed treatments for attention-deficit hyperactivity disorder (ADHD) in children and adults [1].

Dystonic reactions are a well-recognized adverse reaction of many drugs. The causative drugs are commonly ant dopaminergic, such as antipsychotics, antiemetic and less frequently, anticonvulsants and antidepressants. Although the pathophysiology of acute dystonic reactions is still unclear, it is believed to be due to a deficit in central dopamine transmission resulting in overactive striatal acetylcholine release [2].

\section{Case}

The male who is 4 years old and $18 \mathrm{~kg}$ weight patient was referred to the our pediatric emergency department with complaints of involuntary movement of in the arms and in the tongue, slurred speech, vomiting, agitation, hyperactive behaviors. He did not have any family history of psychiatric or physical illness. According to his family's discourse, he had taken methylphenidate $36 \mathrm{mg}$ (prolonged release tablet) before nine hours which is elder brother. In addition his family indicated that he did not use antiemetic or antipsychotics drugs accidentally. The child was admitted to the emergency room and the end of the physical examination was determined back rash, tachycardia (heart rate of 150). On neurological examination: he was well oriented in time, place, and space. All laboratory data including completed blood count, serum electrolytes and renal also liver function tests were within normal limits. Decision was made to give only Biperiden (anticholinergic drug) $2 \mathrm{mg}$ intramuscular injection and check response first. After two hours, patients reverted back to normal movement in the arms and in the tongue. There was no motor or sensory deficit and the boy was discharged on.

\section{Discussion}

$\mathrm{ADHD}$ is one of the most frequently diagnosed neuropsychological disorders in children and adolescents, leading to a developmental impairment of executive functions in the brain. Noradrenergic and dopaminergic neurotransmitter systems have been implicated in the pathophysiology of ADHD [3]. Functional and structural imaging studies has generally implicated prefrontal and striatal regions as neuroimaging correlates of ADHD and MPH response [4].

MPH indicated for the treatment of ADHD in children and adults aged 6-65 years [5]. When consulting Embase and PubMed, few case reports describe children with abnormal movements attributable to methylphenidate. In these reports present a case 10-year-old girl under multiple pharmacologic treatment (imipramine, methylphenidate, valproic acid) who developed oculogyric crisis [6] and other case a 7year-old male patient who presented with orofacial and limb dyskinesia after his first dose of methylphenidate treatment for a diagnosis of attention-deficit/hyperactivity disorder; he was also receiving sodium valproate treatment for epilepsy [7]. But our case differ from others which have mentioned above, in terms of being healthy and exposing only MPH.

According to investigations, monoaminergic system illustrates differences depending on ages $[8,9]$. For this reason, dystonic reaction which occur in our 4 years old child made us think that MPH will be differ from various age groups in terms of treatment and side effect.

\section{Result}

We established this case for shedding light on works which will investigate monoaminergic system's alterations in brain depending on ages. At the same time, we think that MPH will contribute on experimental models which will research effect of dopaminergic or cholinergic on mesolimbic system.

\section{References}

1. Engert V, Pruessner JC (2008) Dopaminergic and noradrenergic contributions to functionality in ADHD: the role of methylphenidate. Curr Neuropharmacol 6: 322-328. 
Citation: Erdogan A, Erdogan H (2015) Methylphenidate-Induced Acute Dystonic Reaction: A case report. J Pharmacovigil 3: 181. doi: 10.4172/2329-6887.1000181

Page 2 of 2

2. Munhoz RP, Moscovich M, Araujo PD, Teive HA (2012) Movement disorders emergencies: a review. Arq Neuropsiquiatr 70: 453-461.

3. Pliszka SR (1998) Comorbidity of attention-deficit/hyperactivity disorder with psychiatric disorder: an overview. J Clin Psychiatry 7: 50-58.

4. Liston C, Malter Cohen M, Teslovich T, LevensonD, Casey BJ (2011) Atypical prefrontal connectivity in attention-deficit/hyperactivity disorder: pathway to disease or pathological end point?. Biol Psychiatry 69: 1168-1177.

5. Concerta $^{\oplus}$ XL $18 \mathrm{mg}-36 \mathrm{mg}$ prolonged release tablets (2013) Summary of product characteristics.

6. Tahiroglu AY, Avci A (2007) Polypharmacy and EPS in a child; a case report. Psychopharmacol Bull 40: 129-133.
7. Yilmaz AE, Donmez A, Orun E, Tas T, Isik B, et al. (2013) Methylphenidate-induced acute orofacial and extremity dyskinesia. J Child Neurol 28: 781-783.

8. Weickert CS, Webster MJ, Gondipalli P, Rothmond D, Fatula RJ, et al (2007) Postnatal alterations in dopaminergic markers in the human prefrontal cortex. Neuroscience 144: 1109-1119.

9. Rothmond DA, Weickert CS, Webster MJ (2012) Developmental changes in human dopamine neurotransmission: Cortical receptors and terminators. BMC Neurosci 13: 18 . 